\title{
An Integrated Approach for Aircraft Engine Performance Estimation and Fault Diagnostics
}

Donald L. Simon

Glenn Research Center, Cleveland, Ohio

Jeffrey B. Armstrong

ASRC Aerospace Corporation, Cleveland, Ohio 


\section{NASA STI Program . . . in Profile}

Since its founding, NASA has been dedicated to the advancement of aeronautics and space science. The NASA Scientific and Technical Information (STI) program plays a key part in helping NASA maintain this important role.

The NASA STI Program operates under the auspices of the Agency Chief Information Officer. It collects, organizes, provides for archiving, and disseminates NASA's STI. The NASA STI program provides access to the NASA Aeronautics and Space Database and its public interface, the NASA Technical Reports Server, thus providing one of the largest collections of aeronautical and space science STI in the world. Results are published in both non-NASA channels and by NASA in the NASA STI Report Series, which includes the following report types:

- TECHNICAL PUBLICATION. Reports of completed research or a major significant phase of research that present the results of NASA programs and include extensive data or theoretical analysis. Includes compilations of significant scientific and technical data and information deemed to be of continuing reference value. NASA counterpart of peer-reviewed formal professional papers but has less stringent limitations on manuscript length and extent of graphic presentations.

- TECHNICAL MEMORANDUM. Scientific and technical findings that are preliminary or of specialized interest, e.g., quick release reports, working papers, and bibliographies that contain minimal annotation. Does not contain extensive analysis.

- CONTRACTOR REPORT. Scientific and technical findings by NASA-sponsored contractors and grantees.
- CONFERENCE PUBLICATION. Collected papers from scientific and technical conferences, symposia, seminars, or other meetings sponsored or cosponsored by NASA.

- SPECIAL PUBLICATION. Scientific, technical, or historical information from NASA programs, projects, and missions, often concerned with subjects having substantial public interest.

- TECHNICAL TRANSLATION. Englishlanguage translations of foreign scientific and technical material pertinent to NASA's mission.

Specialized services also include creating custom thesauri, building customized databases, organizing and publishing research results.

For more information about the NASA STI program, see the following:

- Access the NASA STI program home page at http://www.sti.nasa.gov

- E-mail your question to help@sti.nasa.gov

- Fax your question to the NASA STI Information Desk at 443-757-5803

- Phone the NASA STI Information Desk at 443-757-5802

- Write to: STI Information Desk NASA Center for AeroSpace Information 7115 Standard Drive Hanover, MD 21076-1320 
NASA/TM-2012-217725

GT2012-69905

NAte

An Integrated Approach for Aircraft Engine Performance Estimation and Fault Diagnostics

Donald L. Simon

Glenn Research Center, Cleveland, Ohio

Jeffrey B. Armstrong

ASRC Aerospace Corporation, Cleveland, Ohio

Prepared for the

Turbo Expo 2012

sponsored by the American Society of Mechanical Engineers (ASME)

Copenhagen, Denmark, June 11-15, 2012

National Aeronautics and

Space Administration

Glenn Research Center

Cleveland, Ohio 44135 


\section{Acknowledgments}

This research was conducted under the NASA Aviation Safety Program, Vehicle Systems Safety Technologies Project.

Level of Review: This material has been technically reviewed by technical management.

Available from

NASA Center for Aerospace Information

7115 Standard Drive

Hanover, MD 21076-1320
National Technical Information Service 5301 Shawnee Road Alexandria, VA 22312

Available electronically at http://www.sti.nasa.gov 


\title{
An Integrated Approach for Aircraft Engine Performance Estimation and Fault Diagnostics
}

\author{
Donald L. Simon \\ National Aeronautics and Space Administration \\ Glenn Research Center \\ Cleveland, Ohio 44135 \\ Jeffrey B. Armstrong \\ ASRC Aerospace Corporation \\ Cleveland, Ohio 44135
}

\begin{abstract}
A Kalman filter-based approach for integrated on-line aircraft engine performance estimation and gas path fault diagnostics is presented. This technique is specifically designed for underdetermined estimation problems where there are more unknown system parameters representing deterioration and faults than available sensor measurements. A previously developed methodology is applied to optimally design a Kalman filter to estimate a vector of tuning parameters, appropriately sized to enable estimation. The estimated tuning parameters can then be transformed into a larger vector of health parameters representing system performance deterioration and fault effects. The results of this study show that basing fault isolation decisions solely on the estimated health parameter vector does not provide ideal results. Furthermore, expanding the number of the health parameters to address additional gas path faults causes a decrease in the estimation accuracy of those health parameters representative of turbomachinery performance deterioration. However, improved fault isolation performance is demonstrated through direct analysis of the estimated tuning parameters produced by the Kalman filter. This was found to provide equivalent or superior accuracy compared to the conventional fault isolation approach based on the analysis of sensed engine outputs, while simplifying online implementation requirements. Results from the application of these techniques to an aircraft engine simulation are presented and discussed.
\end{abstract}

\section{Introduction}

Aircraft engine performance trend monitoring and gas path fault diagnostics are closely related technologies that assist operators in managing the health of their gas turbine engine assets. Today, these functions are primarily performed offboard the aircraft within engine health management ground stations, which provide fleet-wide engine health management functionality (Ref. 1). This is accomplished by processing snapshot engine measurement data acquired in-flight. A toplevel description of the aircraft engine performance trend monitoring and gas path fault diagnostics process is given in
Reference 2, and a representation of this process is shown in Figure 1. The process begins by calculating residuals between measured engine outputs and a reference model. Performance trend monitoring is conducted by analyzing the sensor residuals to assess performance changes that a gas turbine engine will naturally incur over time due to turbomachinery deterioration. Typically, this is performed by estimating and trending health parameters reflective of gradual performance deterioration within each major engine module. Since the unknown health parameters typically outnumber the available sensor measurements, this poses an underdetermined estimation problem. Gas path fault diagnostics is the process of detecting and isolating the occurrence of faults impacting engine flow-path performance. It is performed by detecting any rapid or abrupt engine performance changes, and then isolating the most likely cause. Often a single fault isolation approach is applied based on the assumption that engine gas path faults usually occur in an isolated fashion. The observed shift in sensed engine outputs is compared against a collection of known fault type signatures, and the best match is then isolated as the root cause for the event. An illustration of gradual versus rapid performance shifts is shown in Figure 2. Additional details on conventional engine performance trend monitoring and fault diagnostics can be found in References 3 to 6 .

An emerging approach in the field of aircraft engine controls and health management is the inclusion of real-time on-board models for the in-flight estimation of engine performance variations (Refs. 7 to 9). This technology, typically based on Kalman filter concepts, enables the estimation of unmeasured engine performance parameters that can be directly utilized for controls and health management applications. Recently, NASA proposed a model-based gas path health management architecture for on-board performance trend monitoring and gas path fault diagnostics (Refs. 10 and 11). This architecture, shown in Figure 3 , is similar in design to the ground-based architecture shown in Figure 1, and provides the same performance estimation and fault diagnostic functionality. The benefits of the on-board architecture include the real-time continuous monitoring of engine performance and the early diagnosis of fault conditions. This architecture 


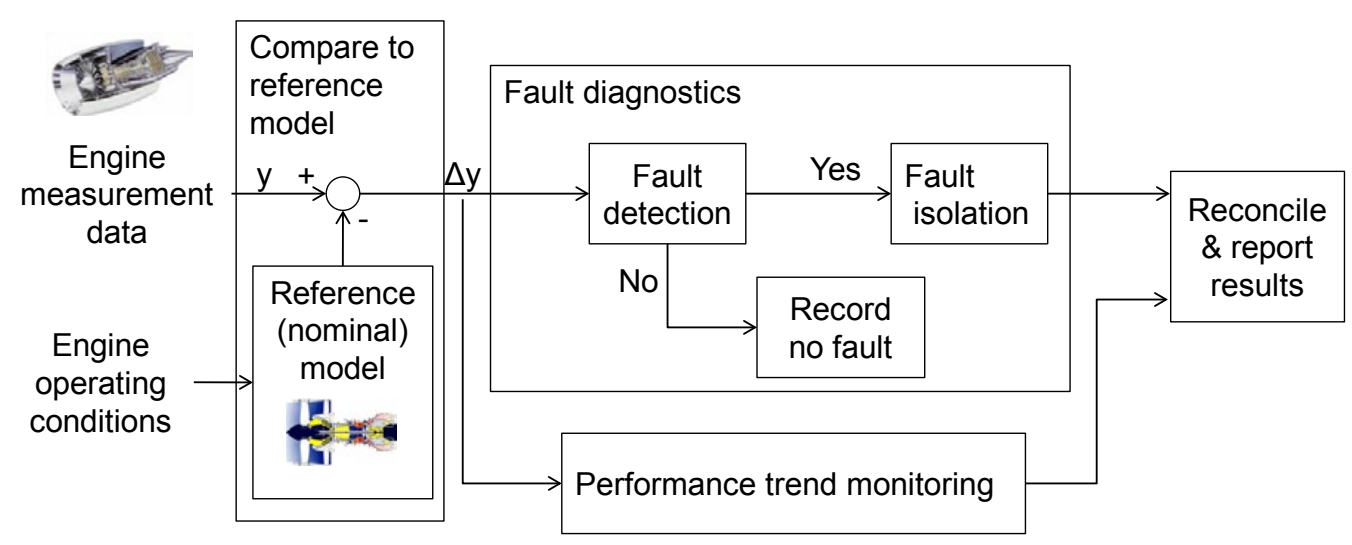

Figure 1.-Ground station performance trend monitoring and gas path diagnostic process.

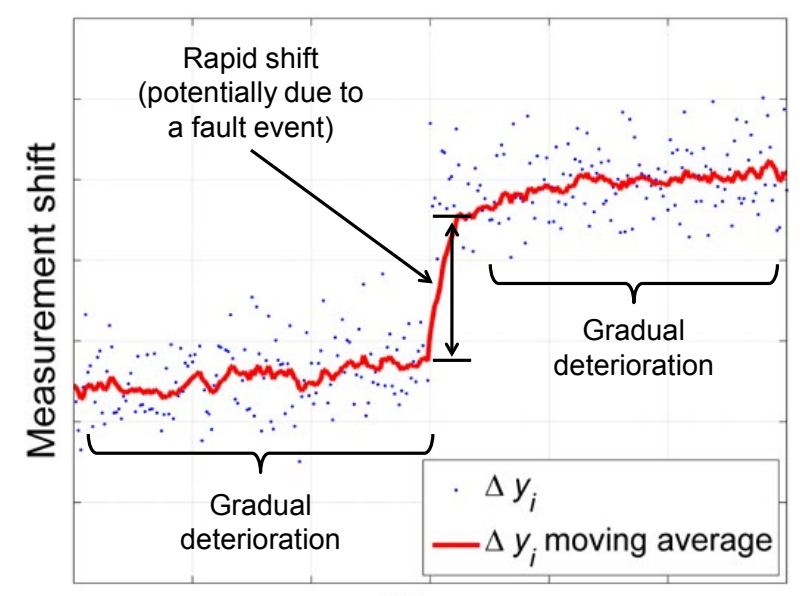

Time

Figure 2.-Gradual versus rapid performance shifts

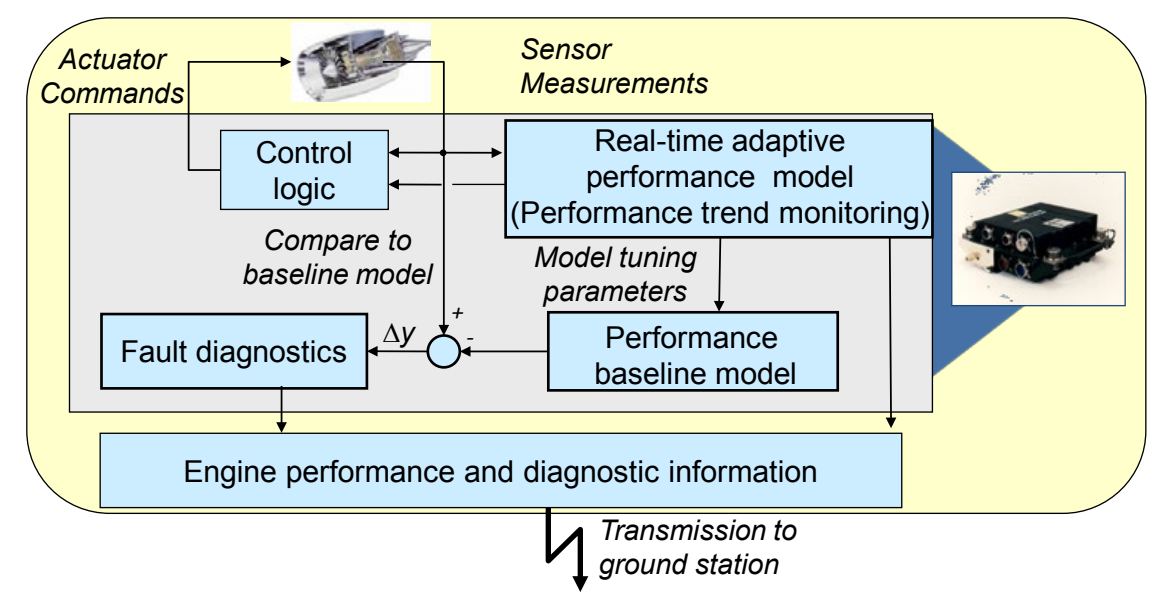

Figure 3.-On-board performance trend monitoring and gas path diagnostic process (original proposed design). 


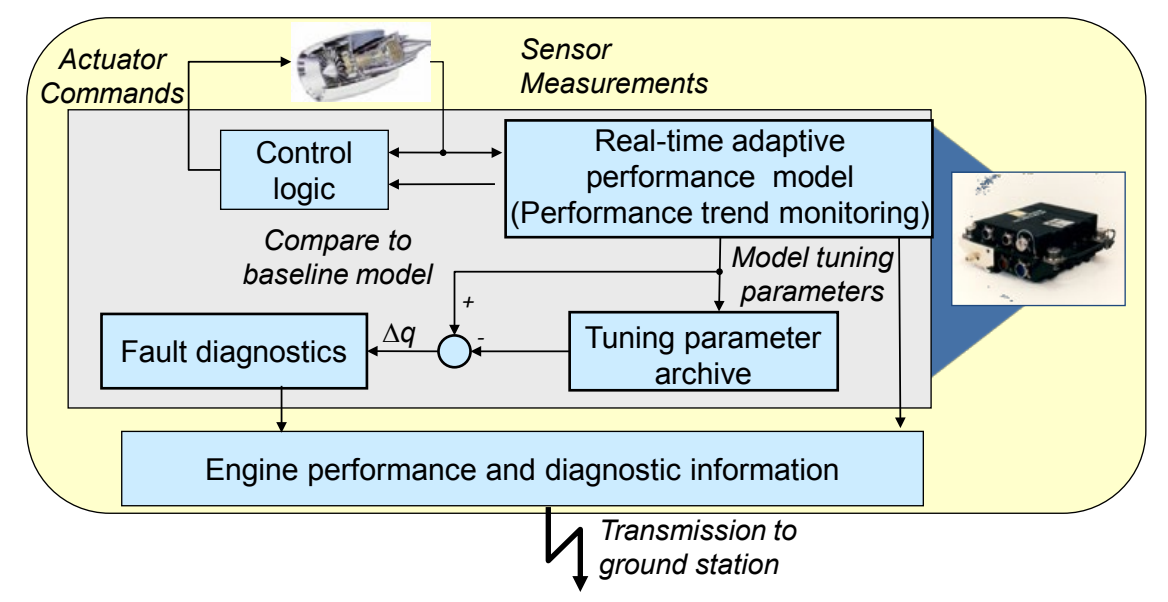

Figure 4.-On-board performance trend monitoring and gas path diagnostic process (simplified proposed design).

contains two engine models designed to operate in parallel. The first model, referred to as the real-time adaptive performance model, applies a Kalman filter to estimate a vector of adjustable model tuning parameters that enable the model to track engine performance over the engine's lifetime of use. To address the underdetermined estimation problem, a previously developed optimal tuner selection strategy is applied to design the Kalman filter (Refs. 12 and 13). This enables the Kalman filter to estimate a reduced-order tuner vector that can be directly transformed into a vector of estimated health parameters reflecting gas path deterioration and/or individual fault magnitudes. The second model, referred to as the performance baseline model, serves as a baseline of recent engine performance. Residuals between the engine and performance baseline model outputs are monitored for fault detection and isolation purposes.

A criticism of the on-board architecture shown in Figure 4 is its complexity as it requires the implementation of two separate on-board engine models. This may not be feasible given on-board processor limitations. In an attempt to design a simpler architecture, this paper will evaluate fault diagnostics based on the model tuning parameters produced by the Kalman filter-based real-time adaptive performance model as shown in Figure 4. Such an approach, if successful, bypasses the need for the on-board performance baseline model.

The remainder of this paper is organized as follows. First, some mathematical preliminaries are given regarding the problem formulation including the linear model representing system dynamics and the formulation of the Kalman filter. The optimal tuner selection methodology that enables the estimation of health parameters when facing underdetermined estimation problems is also introduced. Next, two fault isolation approaches are presented. The first approach bases fault isolation decisions directly on the health parameter estimates. The second approach applies a weighted least squares single fault isolation strategy that seeks to determine

the fault type that best matches the observed signature in the Kalman filter estimated model tuning parameters. This is followed by an example application of the techniques to a linear turbofan engine model. Finally, conclusions are presented.

\section{Nomenclature}

$$
\begin{aligned}
& A, A_{x h}, A_{x q} \\
& B, B_{x h}, B_{x q}, \\
& C, C_{x h}, C_{x q}, \\
& D, L, M \\
& \text { C-MAPSS }
\end{aligned}
$$

$D_{M}$

$H$

HPC

HPT

I

$K_{\infty}$

LPC

LPT

$P$

$P M C$

$P_{\infty}$

$Q, Q_{x h}, Q_{x q}$

$R$

SSEE

$V^{*}$

VSV system matrices

Commercial Modular Aero-Propulsion System Simulation

Mahalanobis distance

fault influence matrix

high pressure compressor

high pressure turbine

identity matrix

Kalman filter gain

low pressure compressor

low pressure turbine

covariance matrix

probability of misclassification

Kalman filter state estimation covariance matrix

process noise covariance matrices

measurement noise covariance matrix

sum of squared estimation errors

transformation matrix relating $h$ to $q$

variable stator vane 


$\begin{array}{ll}\text { VBV } & \text { variable bleed valve } \\ \text { Wf } & \text { fuel flow } \\ W S S R & \text { weighted sum of squared residuals } \\ h & \text { health parameter vector } \\ q & \text { Kalman filter tuning parameter vector } \\ u & \text { actuator command vector } \\ v & \text { measurement noise vector } \\ w & \text { process noise vector } \\ x & \text { state vector } \\ x_{x h} & \text { augmented state vector }(x \text { and } h) \\ x_{x q} & \text { reduced-order state vector }(x \text { and } q) \\ y & \text { vector of measured outputs }\end{array}$

$\begin{array}{ll}\text { Subscripts } & \\ f & \text { fault } \\ h & \text { health parameter vector } \\ k & \text { discrete time step index } \\ q & \text { tuner vector } \\ x h & \text { augmented state vector }(x \text { and } h) \\ x q & \text { reduced-order state vector }(x \text { and } q) \\ \text { ss } & \text { steady-state value }\end{array}$

\section{Superscripts}

$\begin{array}{ll}\dagger & \text { pseudo-inverse } \\ \sim & \text { estimated value } \\ \sim & \text { error value } \\ \mathrm{T} & \text { transpose }\end{array}$

\section{Problem Formulation}

Problem formulation will begin by reviewing the steps necessary to design a Kalman filter applying the optimal tuner selection methodology described in Reference 12. First, consider the discrete linear time-invariant engine state space equations about a linear design point given as

$$
\begin{aligned}
& x_{k+1}=A x_{k}+B u_{k}+L h_{k}+w_{k} \\
& y_{k}=C x_{k}+D u_{k}+M h_{k}+v_{k}
\end{aligned}
$$

where $k$ is the time index, $x$ is the vector of state variables, $u$ is the vector of control inputs, and $y$ is the vector of measured outputs. The vector $h$, where $h \in \mathbb{R}^{p}$, represents the engine health parameters, which induce shifts in other variables as the health parameters deviate from their nominal values. The vectors $w$ and $v$ are uncorrelated zero-mean white noise input sequences. $Q$ will be used to denote the covariance of $w$, and $R$ to denote the covariance of $v$. The matrices $A, B, C, D, L$, and $M$ are of appropriate dimensions. Through algebraic manipulation Equation (1) can be re-written such that $h$ is concatenated with $x$ to form an augmented state vector, $x_{x h}$, as shown in Equation (2). Since engine performance deterioration is very slowly evolving relative to other engine dynamics, $h$ is here modeled without dynamics.

$$
\begin{aligned}
{\left[\begin{array}{l}
x_{k+1} \\
h_{k+1}
\end{array}\right] } & =\underbrace{\left[\begin{array}{rr}
A & L \\
0 & I
\end{array}\right]}_{A_{x h}} \underbrace{\left[\begin{array}{c}
x_{k} \\
h_{k}
\end{array}\right]}_{x_{x h, k}}+\underbrace{\left[\begin{array}{c}
B \\
0
\end{array}\right]}_{B_{x h}} u_{k}+\underbrace{\left[\begin{array}{c}
w_{k} \\
w_{h, k}
\end{array}\right]}_{w_{x h, k}} \\
& =A_{x h} x_{x h, k}+B_{x h} u_{k}+w_{x h, k} \\
y_{k}= & \underbrace{\left[\begin{array}{ll}
C & M
\end{array}\right]}_{C_{x h}} \underbrace{\left[\begin{array}{l}
x_{k} \\
h_{k}
\end{array}\right]}_{x_{x h, k}}+D u_{k}+v_{k} \\
= & C_{x h} x_{x h, k}+D u_{k}+v_{k}
\end{aligned}
$$

The vector $w_{x h}$ is zero-mean white noise associated with the augmented state vector, $\left[x^{\mathrm{T}} h^{\mathrm{T}}\right]^{\mathrm{T}} . w_{x h}$ consists of the original state process noise, $w$, concatenated with the process noise associated with the health parameter vector, $w_{h}$.

$$
w_{x h, k}=\left[\begin{array}{c}
w_{k} \\
w_{h, k}
\end{array}\right]
$$

The covariance of $w_{x h}$, denoted as $Q_{x h}$, is necessary for Kalman filter formulation as will be discussed later in the paper.

\section{Reduced-Order State Space Model}

To enable Kalman filter formulation for an underdetermined estimation problem, a reduced-order state space model must be constructed. This is accomplished by defining a model tuning parameter vector, $q$, which is a linear combination of all health parameters, $h$, given by

$$
q=V^{*} h
$$

where $q \in \mathbb{R}^{m}, h \in \mathbb{R}^{p}, m<p$, and $V^{*}$ is an $m \times p$ transformation matrix of rank $m$, which relates $h$ to $q$. Although $q$ is a linear combination of health parameters, the elements of $q$ do not have any physical meaning. Their purpose is to allow an accurate estimation of unmeasured engine parameters. However, given an estimate of $q$ (i.e., $\hat{q}$ ), an approximation of the health parameter vector, $\hat{h}$, can be obtained as 


$$
\hat{h}=V^{* \dagger} \hat{q}
$$

where $V^{* \dagger}$ is the pseudo-inverse of $V^{*}$. Substituting Equation (5) into Equation (2) yields the following reduced-order state space equations that will be used to formulate the Kalman filter

$$
\begin{aligned}
\underbrace{\left[\begin{array}{c}
x_{k+1} \\
q_{k+1}
\end{array}\right]}_{x_{x q, k+1}} & =\underbrace{\left[\begin{array}{cc}
A & L V^{* \dagger} \\
0 & I
\end{array}\right]}_{A_{x q}} \underbrace{\left[\begin{array}{c}
x_{k} \\
q_{k}
\end{array}\right]}_{x_{x q, k}}+\underbrace{\left[\begin{array}{c}
B \\
0
\end{array}\right]}_{B_{x q}} u_{k}+\underbrace{\left[\begin{array}{c}
w_{k} \\
w_{q, k}
\end{array}\right]}_{w_{x q, k}} \\
& =A_{x q} x_{x q, k}+B_{x q} u_{k}+w_{x q, k} \\
y_{k} & =\underbrace{\left[\begin{array}{cc}
C & M V^{* \dagger}
\end{array}\right]}_{C_{x q}} \underbrace{\left[\begin{array}{c}
x_{k} \\
q_{k}
\end{array}\right]+D u_{k}+v_{k}}_{x_{x q, k}} \\
& =C_{x q} x_{x q, k}+D u_{k}+v_{k}
\end{aligned}
$$

For the reduced-order system, the state process noise, $w_{x q}$, and its associated covariance, $Q_{x q}$, are a function of the full-order state process noise and covariance (i.e., $w_{x h}$ and $Q_{x h}$ ) and the transformation matrix, $V^{*}$

$$
\begin{aligned}
w_{x q, k} & =\left[\begin{array}{cc}
I & 0 \\
0 & V^{*}
\end{array}\right] w_{x h, k}=\left[\begin{array}{cc}
I & 0 \\
0 & V^{*}
\end{array}\right]\left[\begin{array}{c}
w_{k} \\
w_{h, k}
\end{array}\right], \\
Q_{x q} & =\left[\begin{array}{cc}
I & 0 \\
0 & V^{*}
\end{array}\right] Q_{x h}\left[\begin{array}{cc}
I & 0 \\
0 & V^{*}
\end{array}\right]^{T}
\end{aligned}
$$

Here, as in many Kalman filter designs, the specification of system process noise covariance, $Q_{x h}$, can be treated as a design parameter. Increasing the process noise will cause the ensuing Kalman filter to place more emphasis on the measurements, and less on the process model. An evaluation of the effect of $Q_{x h}$ specification on the estimation accuracy and responsiveness of a Kalman filter applying the optimal tuner selection methodology can be found in Reference 13.

\section{Kalman Filter Formulation}

In this study, steady-state Kalman filtering is applied. This means that although the Kalman filter is a dynamic system, the state estimation error covariance matrix and the Kalman gain matrix are invariant; instead of updating these matrices each time step, they are held constant. Given the reduced-order linear state space equations shown in Equation (6), the state estimation error covariance matrix, $P_{\infty}$, is calculated by solving the following Riccati equation (Ref. 14)

$$
\begin{aligned}
P_{\infty}= & A_{x q} P_{\infty} A_{x q}^{T} \cdots \\
& -A_{x q} P_{\infty} C_{x q}^{T}\left(C_{x q} P_{\infty} C_{x q}^{T}+R\right)^{-1} C_{x q} P_{\infty} A_{x q}^{T}+Q_{x q}
\end{aligned}
$$

The steady-state Kalman filter gain, $K_{\infty}$, can then be calculated as follows (Ref. 14)

$$
K_{\infty}=P_{\infty} C_{x q}^{T}\left(C_{x q} P_{\infty} C_{x q}^{T}+R\right)^{-1}
$$

and, assuming steady-state, open-loop operation $(u=0)$, the Kalman filter estimator takes the following form

$$
\hat{x}_{x q, k}=\left[\begin{array}{l}
\hat{x}_{k} \\
\hat{q}_{k}
\end{array}\right]=A_{x q} \hat{x}_{x q, k-1}+K_{\infty}\left(y_{k}-C_{x q} A_{x q} \hat{x}_{x q, k-1}\right)
$$

Using Equation (5), the reduced-order state vector estimate, $\hat{x}_{x q}$, produced by Equation (10) can be transformed into an estimate of the augmented state vector as follows

$$
\hat{x}_{x h, k}=\left[\begin{array}{l}
\hat{x}_{k} \\
\hat{h}_{k}
\end{array}\right]=\left[\begin{array}{cc}
I & 0 \\
0 & V^{*, \dagger}
\end{array}\right] \hat{x}_{x q, k}=[\begin{array}{cc}
I & 0 \\
0 & V^{*, \dagger}
\end{array} \underbrace{\left[\begin{array}{l}
\hat{x}_{k} \\
\hat{q}_{k}
\end{array}\right]}_{\hat{x}_{x q, k}}
$$

\section{Optimal Transformation Matrix Selection}

As presented in Reference 12, the estimation accuracy of the Kalman filter is directly dependent on the selection of the transformation matrix, $V^{*}$. This gives rise to the optimization problem of selecting $V^{*}$ to minimize the estimation error in the parameters of interest. This can be accomplished by conducting an optimal iterative search to select a $V^{*}$ matrix that minimizes the mean sum of squared estimation errors (SSEE) in the parameters of interest

$$
\underset{V^{*} \in \mathbb{R}^{m \times p}}{\arg \min } \operatorname{SSEE}\left(V^{*}\right)
$$

Readers are referred to Reference 12 for the derivation of health parameter mean SSEE as a function of $V^{*}$ under openloop steady-state operating conditions.

\section{Analysis of Kalman Filter Parameter Estimates for Gas Path Fault Isolation}

As opposed to performing fault isolation by analyzing sensor measurements directly, this study proposes the monitoring of the estimated parameters produced by the Kalman filter. Like the sensed measurement illustration shown in Figure 2, Kalman filter-produced estimated parameters are expected to undergo a discernable change when the engine experiences a gas path fault. However, monitoring the Kalman filter outputs directly helps simplify the diagnostic system design. While it will require the archival of past tuning parameter values in order to calculate the magnitude of any 
recent abrupt/rapid change, it eliminates the need to implement and maintain a complete reference model for diagnostic purposes (e.g., the Performance Baseline Model previously shown in Figure 3). Although diagnostics typically consist of the two-step process of fault detection and fault isolation (see Figure 1), this study will exclusively focus on the fault isolation aspect of the problem while assuming that fault detection has already successfully occurred. While not explicitly analyzed or demonstrated, it is anticipated that event detection techniques similar to those commonly applied to monitor for changes in sensed engine outputs (e.g., see Refs. 15 to 17) can be applied to detect event changes in estimated Kalman filter outputs as well. The fault isolation techniques considered in this study consist of two separate approaches designed to analyze Kalman filter-produced parameter estimates. The first approach is designed to analyze the health parameter estimates, $\hat{h}$ (given by Eq. (11)), while the second approach is designed to analyze the tuning parameter estimates, $\hat{q}$ (given by Eq. (10)). These two approaches are further discussed in the sections below.

\section{Fault Isolation Through $\hat{h}$ Analysis}

The first fault isolation approach performs fault isolation based on the estimated health parameters that undergo the largest magnitude change (relative to recently archived values). For example in a turbofan engine, if the largest estimated health parameter changes are observed in fan efficiency and fan flow capacity a fan fault is declared. In addition to turbomachinery module faults, the capability to isolate other gas path system fault types may be addressed by incorporating additional health parameters (e.g., health parameters representing actuator and sensor biases). Doing so increases the number of health parameters, resulting in the following updated state-space equations

$$
\begin{aligned}
& x_{k+1}=A x_{k}+B u_{k}+\left[\begin{array}{ll}
L & L_{f}
\end{array}\right]\left[\begin{array}{c}
h_{k} \\
h_{f, k}
\end{array}\right]+w_{k} \\
& y_{k}=C x_{k}+D u_{k}+\left[\begin{array}{ll}
M & M_{f}
\end{array}\right]\left[\begin{array}{c}
h_{k} \\
h_{f, k}
\end{array}\right]+v_{k}
\end{aligned}
$$

where $h_{f}$ represents non-turbomachinery module faults, and the matrices $L_{f}$ and $M_{f}$ reflect the effects of those additional faults in the system states and sensed outputs, respectively. As the optimal tuner selection methodology enables the estimation of any number of health parameters, estimation of the expanded health parameter vector is feasible. However, this will require selection of a $V^{*}$ matrix optimized, and appropriately sized, for the expanded health parameter configuration.

\section{Fault Isolation Through $\hat{\boldsymbol{q}}$ Analysis}

While the previously described fault isolation approach based on $\hat{h}$ analysis is simple and intuitive as it provides a direct estimate of fault magnitude, it does have limitations. It is predicated on the assumption that when a fault occurs, the resulting change in health parameter estimates will be sparsely concentrated in those health parameters associated with the fault. However, due to the underdetermined nature of the estimation problem the occurrence of a fault will often result in a "smearing" of estimates across the entire vector of estimated health parameters (Ref. 18). Furthermore, the underdetermined nature of the Kalman estimation problem worsens as the dimension of $h_{f}$ expands to incorporate more fault types. Borguet and Léonard presented an encouraging sparse isolation approach for underdetermined least squares estimation problems (Ref. 19). However, it is unclear if this approach can be extended to online Kalman filter estimation applications. Instead of basing fault isolation decisions on those health parameters that undergo the largest change, an alternative fault isolation strategy is to monitor for specific fault signatures contained within the estimated reduced-order tuner vector, $\hat{q}$, produced by the Kalman filter. This technique is analogous to the single-fault isolation strategy that is commonly applied to sensed engine outputs. To apply this technique it is first necessary to determine the $\hat{q}$ signature that corresponds to each fault type. This derivation will be made assuming quasi-steady-state open-loop operating conditions and assuming that the Kalman filter has been designed based upon the reduced-order state-space model equations shown in (6). These derivations will take advantage of the following expected value properties at steady-state open-loop operating conditions

$$
\begin{aligned}
& E\left[x_{k+1}\right]=E\left[x_{k}\right]=x_{s s} \\
& E\left[\begin{array}{c}
h_{k} \\
h_{f, k}
\end{array}\right]=\left[\begin{array}{c}
h \\
h_{f}
\end{array}\right] \\
& E\left[y_{k}\right]=y_{s s} \\
& E\left[u_{k}\right]=0 \\
& E\left[w_{k}\right]=0 \\
& E\left[v_{k}\right]=0 \\
& E\left[\hat{x}_{x q, k}\right]=E\left[\hat{x}_{x q, k-1}\right]=\hat{x}_{x q, s s}
\end{aligned}
$$

By taking expected values of both sides of the ensuing Kalman filter shown in Equation (10), the expected value of $\hat{x}_{x q, k}$ can be obtained as a function of $y_{s s}$ 


$$
\begin{aligned}
E\left[\hat{x}_{x q, k}\right] & =A_{x q} E\left[\hat{x}_{x q, k-1}\right] \ldots \\
& +K_{\infty}\left(E\left[y_{k}\right]-C_{x q} A_{x q} E\left[\hat{x}_{x q, k-1}\right]\right)
\end{aligned}
$$

Next, the steady-state engine sensed outputs as a function of the fault condition will be derived. The derivation will be based upon the system equations shown in Equation (13) with the expanded health parameter vector to encompass additional fault types. Taking expected values produces

$$
\begin{aligned}
& E\left[x_{k+1}\right]=A E\left[x_{k}\right]+B E\left[u_{k}\right] \ldots \\
& +\left[\begin{array}{ll}
L & L_{f}
\end{array}\right] E\left[\begin{array}{c}
h_{k} \\
h_{f, k}
\end{array}\right]+E\left[w_{k}\right] \\
& x_{s s}=A x_{s s}+\left[\begin{array}{ll}
L & L_{f}
\end{array}\right]\left[\begin{array}{c}
h \\
h_{f}
\end{array}\right] \\
& x_{s s}=(I-A)^{-1}\left[\begin{array}{ll}
L & L_{f}
\end{array}\right]\left[\begin{array}{c}
h \\
h_{f}
\end{array}\right] \\
& E\left[y_{k}\right]=C E\left[x_{k}\right]+D E\left[u_{k}\right] \ldots \\
& +\left[\begin{array}{ll}
M & M_{f}
\end{array}\right] E\left[\begin{array}{c}
h_{k} \\
h_{f, k}
\end{array}\right]+E\left[v_{k}\right] \\
& y_{s s}=C x_{s s}+\left[\begin{array}{ll}
M & M_{f}
\end{array}\right]\left[\begin{array}{c}
h \\
h_{f}
\end{array}\right] \\
& y_{s s}=\underbrace{\left(C(I-A)^{-1}\left[\begin{array}{ll}
L & L_{f}
\end{array}\right]+\left[\begin{array}{ll}
M & M_{f}
\end{array}\right]\right)}_{G_{y}}\left[\begin{array}{l}
h \\
h_{f}
\end{array}\right] \\
& y_{s s}=G_{y}\left[\begin{array}{c}
h \\
h_{f}
\end{array}\right]
\end{aligned}
$$

Substituting Equation (17) into Equation (15) enables the calculation of the reduced-order state vector as a function of the fault condition

$$
\hat{x}_{x q, s s}=\left(I-A_{x q}+K_{\infty} C_{x q} A_{x q}\right)^{-1} K_{\infty} G_{y}\left[\begin{array}{c}
h \\
h_{f}
\end{array}\right]
$$

Recall that $x_{x q}$ is the concatenation of $x$ and $q$ (see Eqs. (6) and (10)). Therefore, based on Equation (18), an expression for the steady-state reduced-order tuner vector as a function of the fault condition can be obtained

$$
\begin{aligned}
& \hat{q}_{s s}=\underbrace{\left[\begin{array}{ll}
0 & I
\end{array}\right]\left(I-A_{x q}+K_{\infty} C_{x q} A_{x q}\right)^{-1} K_{\infty} G_{y}}_{G_{q}}\left[\begin{array}{c}
h \\
h_{f}
\end{array}\right] \\
& \hat{q}_{s s}=G_{q}\left[\begin{array}{c}
h \\
h_{f}
\end{array}\right]
\end{aligned}
$$

The above equation can be used to construct a fault influence coefficient matrix, denoted as $H$, that relates fault effects to Kalman filter tuning parameter estimates under steady-state conditions. This is performed off-line (i.e., during the system design phase) by individually perturbing health parameters, or combinations of health parameters, representing each system fault type to determine the corresponding change induced in the elements of the vector $\hat{q}_{s s}$. Dividing the change in $\hat{q}_{s s}$ by the inserted fault magnitude produces a column of the fault influence coefficient matrix. Once a fault influence matrix column has been calculated for each fault type they can be concatenated to form the matrix. This gives rise to the following quasi-steady-state equation representing $\hat{q}$ as a function of the fault condition

$$
\hat{q}=H f+v_{q}
$$

where the vector $f$ represents system faults and $v_{q}$ represents random uncertainty in the $\hat{q}$ estimates with covariance $P_{q} . P_{q}$ can be analytically derived based upon the system matrices, measurement noise covariance, and the Kalman gain as shown in Reference 12. It is important to emphasize that the dimension and elements of the fault vector $f$ do not have to be equivalent to those of $\left[h h_{f}\right]^{\mathrm{T}}$. For example, it may be desirable to model a turbomachinery module fault as a combined shift in efficiency and flow capacity health parameters as opposed to separating them into two separate faults. Given Equation (20), a least squares fault isolation approach can be formulated. Here, each fault type is evaluated individually, and the hypothesized fault type that best matches the observed $\hat{q}$ signature in a weighted least squares sense is isolated as the fault type. For example, for the $i^{\text {th }}$ fault type the estimated fault magnitude is calculated as

$$
\hat{f}_{i}=\left(H_{i}^{T} P_{q}^{-1} H_{i}\right)^{-1} H_{i}^{T} P_{q}^{-1} \hat{q}
$$

where $H_{i}$ is the column of the $H$ matrix corresponding to the $i^{\text {th }}$ fault type, and the scalar $\hat{f}_{i}$ is the estimated magnitude of the $i^{\text {th }}$ fault type that produces the best match of the observed $\hat{q}$ signature in a weighted least squares sense. The resulting $\hat{f}_{i}$ estimate is then used to calculate the estimation error residual vector for the $i^{\text {th }}$ fault type as 


$$
\begin{aligned}
\tilde{\hat{q}}_{i} & =\hat{q}-\hat{\hat{q}}_{i} \\
& =\hat{q}-H_{i} \cdot \hat{f}_{i} \\
& =\hat{q}-H_{i}\left(H_{i}^{T} P_{q}^{-1} H_{i}\right)^{-1} H_{i}^{T} P_{q}^{-1} \hat{q} \\
& =\left(I-H_{i}\left(H_{i}^{T} P_{q}^{-1} H_{i}\right)^{-1} H_{i}^{T} P_{q}^{-1}\right) \hat{q}
\end{aligned}
$$

The weighted sum of squared residuals for the $i^{\text {th }}$ hypothesized fault type is calculated as

$$
W S S R_{i}=\tilde{\hat{q}}_{i}^{T} P_{q}^{-1} \tilde{\hat{q}}_{i}
$$

After WSSR's are calculated for each potential fault type they are compared, and the hypothesized fault type that produces the minimum WSSR is isolated as the fault cause.

\section{Probability of Fault Misclassification}

This subsection will introduce a stochastic approach for calculating the probability of fault misclassification for the single fault weighted least squares isolation approach previously presented. This information will be incorporated into the optimal iterative search routine designed to select the transformation matrix $V^{*}$. Doing so will make tuning parameter selection a dual-objective function of minimizing estimation error within the parameters of interest while also minimizing the probability of misclassification when performing fault isolation. Several simplifying assumptions are made in producing this calculation. First, the calculation applied to approximate the misclassification rate only considers the probability of misclassification between fault pair combinations (i.e., makes the assumption that only two fault classes exist). The two-class misclassification rate results across all fault pairs are then summed to estimate an overall misclassification rate. Calculating the two-class misclassification rate is readily tractable compared to multi-class misclassification rate given three or more faults. While this simplification does not enable an exact calculation of the overall misclassification rate for a given fault type, it is effective for identifying fault pairs at high risk of misclassification. Second, misclassification rates are based on an assumed mean fault magnitude for each fault type. While this assumption does not fully account for the fact that faults can be of varying severity or magnitude it is effective for identifying the misclassification probability for faults of average severity. Let us consider a fault of a given type, $a$, and magnitude, $f_{a}$. From Equation (20) the expected estimated tuner vector under this condition becomes $q_{a}=H_{a} f_{a}$. The probability that a $\hat{q}$ observation collected when fault $f_{a}$ is present is misclassified as fault type $b$ (assumed to be of equivalent probability and equivalent $\hat{q}$ covariance as fault type $a$ ) is given as (Ref. 20)

$$
P M C_{b \mid a}=1-\Phi\left(\frac{1}{2} \cdot D_{M}\right)
$$

where $P M C_{b \mid a}$ is the probability of misclassifying fault type $a$ as $b, \Phi$ is the standard normal distribution function, and $D_{M}$ is the Mahalanobis distance defined as

$$
D_{M}=\min \left\{\begin{array}{c}
\sqrt{\left(q_{a}-q_{b}\right)^{T} P_{q}^{-1}\left(q_{a}-q_{b}\right)} \\
- \text { or }-\sqrt{ } \\
\sqrt{\left(q_{a}+q_{b}\right)^{T} P_{q}^{-1}\left(q_{a}+q_{b}\right)}
\end{array}\right\}
$$

$\sqrt{ }$

The above expression accounts for the fact that the least squares estimation approach is able to produce bi-directional fault estimates of either a positive or negative magnitude. The sign that produces the minimum distance will have the largest contribution to the misclassification rate. In Equation (25), $q_{b}$ is the estimated tuner vector for fault type $b$, scaled to be the same weighted length as $q_{a}$ as shown in the equation below.

$$
q_{b}=H_{b} \frac{\sqrt{q_{a}^{T} P_{q}^{-1} q_{a}}}{\sqrt{H_{b}^{T} P_{q}^{-1} H_{b}}}
$$

The above equations allow approximate measures for the probability of misclassification $P M C_{b \mid a}$ for each fault pair to be included within the optimization routine designed to select the $V^{*}$ matrix.

\section{Turbofan Engine Example}

A linear model extracted from the NASA Commercial Modular Aero-Propulsion System Simulation (C-MAPSS) high-bypass turbofan engine model (Ref. 21) is used to evaluate the methodology. The linear model has two state variables and three control actuators as shown in Table 1. Also shown in Table 1 are 13 health parameters used for the purposes of this study. This includes 10 efficiency and flow capacity health parameters associated with the major rotating modules of the engine, plus 3 actuator bias health parameters. The model's six sensed outputs, and corresponding sensor noise standard deviation, are shown in Table 2. The gas path fault types and corresponding health parameter magnitude shifts applied to simulate these fault types are shown in Table 3. The values shown in Table 3 reflect rapid/abrupt deltas, or shifts, in these parameters relative to a recently archived baseline. These values were manually chosen through trial and error to present challenging, yet representative, fault isolation scenarios. 
TABLE 1.-STATE VARIABLES, HEALTH PARAMETERS, AND ACTUATORS

\begin{tabular}{|l|l|l|}
\hline \multicolumn{1}{|c|}{$\begin{array}{c}\text { State } \\
\text { variables }\end{array}$} & \multicolumn{1}{|c|}{ Actuators } & \multicolumn{1}{c|}{$\begin{array}{c}\text { Health } \\
\text { parameters }\end{array}$} \\
\hline $\begin{array}{l}\text { Nf }- \text { fan speed }- \text { core speed } \\
\text { VSV - fuel flow } \\
\text { vane } \\
\text { VBV - variable stator } \\
\text { valve }\end{array}$ & $\begin{array}{l}\text { Fan efficiency } \\
\text { Fan flow capacity }\end{array}$ \\
& & LPC efficiency \\
& & LPC flow capacity \\
& & HPC efficiency \\
& HPC flow capacity \\
& & HPT efficiency \\
& & HPT flow capacity \\
& & LPT efficiency \\
& & LPT flow capacity \\
& & Wf bias \\
& & VSV bias \\
& & VBV bias \\
\hline
\end{tabular}

TABLE 2.-SENSED OUTPUTS AND STANDARD DEVIATION AS PERCENT OF OPERATING POINT TRIM VALUES

\begin{tabular}{|l|c|}
\hline \multicolumn{1}{|c|}{$\begin{array}{c}\text { Sensed } \\
\text { output }\end{array}$} & $\begin{array}{c}\text { Standard deviation, } \\
\%\end{array}$ \\
\hline $\mathrm{Nf}-$ fan speed & 0.005 \\
$\mathrm{Nc}-$ core speed & 0.005 \\
T24 - HPC inlet total temperature & 0.015 \\
Ps30- HPC exit static pressure & 0.010 \\
T30 - HPC exit total temperature & 0.015 \\
T48 - Exhaust gas temperature & 0.015 \\
\hline
\end{tabular}

TABLE 3.-GAS PATH FAULT TYPES AND MAGNITUDES

\begin{tabular}{|l|l|}
\hline \multicolumn{1}{|c|}{ Fault type } & \multicolumn{1}{c|}{$\begin{array}{c}\text { Health parameter } \\
\text { shifts }\end{array}$} \\
\hline Fan & $-2 \% \eta_{\mathrm{fan}}$ and $-2 \% \gamma_{\mathrm{fan}}$ \\
LPC & $-4 \% \eta_{\mathrm{LPC}}$ and $-4 \% \gamma_{\mathrm{LPC}}$ \\
HPC & $-2 \% \eta_{\mathrm{HPC}}$ and $-2 \% \gamma_{\mathrm{HPC}}$ \\
HPT & $-2 \% \eta_{\mathrm{HPT}}$ and $+2 \% \gamma_{\mathrm{HPT}}$ \\
LPT & $-2 \% \eta_{\mathrm{LPT}}$ and $+2 \% \gamma_{\mathrm{LPT}}$ \\
Wf bias & $-2 \% \mathrm{Wf}$ bias \\
VSV bias & $-2 \% \mathrm{VSV}$ bias \\
VBV bias & $-10 \% \mathrm{VBV}$ bias \\
\hline
\end{tabular}

The linear model is used as the truth model for this application example. The model is run open-loop, so all control inputs remain at 0 , unless an actuator bias fault is present. In emulating turbomachinery performance deterioration effects, deviations in the first ten health parameters are considered. Variations in these health parameters are assumed to be uncorrelated, and randomly shifted from their trim conditions with a standard deviation of \pm 0.02 ( \pm 2 percent). Since a parameter's variance is equal to its standard deviation squared, the health parameter covariance matrix, $P_{h}$, is defined as a diagonal matrix with all diagonal elements equal to 0.0004 .

For evaluation purposes, the optimal tuner selection methodology was applied to produce three separate Kalman filter designs for application at a single open-loop operating point. The first Kalman filter was designed to minimize the sum of squared estimation errors (SSEE) in the first 10 health parameters listed in Table 1. In constructing this Kalman filter, the system state space equations were assumed to be of the form shown in Equation (1), and the three health parameters associated with actuator bias were not included in the design. Furthermore, fault probability of misclassification was not considered in the selection of the $V^{*}$ matrix. The second Kalman filter was designed in accordance with Equation (13) assuming all 13 health parameters (the 10 representing turbomachinery deterioration plus the three actuator bias health parameters). The second Kalman filter required selection of a $V^{*}$ matrix with three additional columns to accommodate the additional health parameters. Here, $V^{*}$ matrix selection was performed to minimize the sum of squared estimation errors (SSEE) in the first 10 health parameters listed in Table 1 . While the second Kalman filter design does provide an estimate of all 13 health parameters, the accuracy of the 3 health parameters reflecting actuator bias was not considered during the $V^{*}$ matrix selection process. ${ }^{1}$ The associated fault isolation strategy was to identify the health parameter(s) that exhibited the largest change in accordance with the eight fault types listed in Table 3 . The third Kalman filter was designed in accordance with Equation (1) to enable an estimate of the first 10 health parameters shown in Table 1 to be produced. Optimal tuner selection was performed with the two-fold objective of minimizing the SSEE in the first 10 health parameters and minimizing the probability of fault misclassification between all fault pairs. A summary of the three Kalman filter designs is shown in Table 4.

TABLE 4.-SUMMARY OF KALMAN FILTER DESIGNS

\begin{tabular}{|c|c|c|c|}
\hline $\begin{array}{c}\text { Kalman } \\
\text { filter } \\
\text { design }\end{array}$ & $\begin{array}{c}\text { Size of } h \text { used } \\
\text { in design of } \\
\text { Kalman filter }\end{array}$ & $\begin{array}{c}V^{*} \\
\text { optimization } \\
\text { objective }\end{array}$ & $\begin{array}{c}\text { Fault isolation } \\
\text { strategy }\end{array}$ \\
\hline 1 & $\begin{array}{c}10 \text { health } \\
\text { parameters }\end{array}$ & Minimize $\hat{h}$ SSEE & $\hat{q}$ least squares \\
\hline 2 & $\begin{array}{c}13 \text { health } \\
\text { parameters }\end{array}$ & $\begin{array}{c}\text { minimize } \hat{h} \text { SSEE } \\
\text { (n elements } 1 \text { to } 10 \\
\text { only) }\end{array}$ & $\begin{array}{c}\hat{h} \text { maximum } \\
\text { element(s) }\end{array}$ \\
\hline 3 & $\begin{array}{c}10 \text { health } \\
\text { parameters }\end{array}$ & $\begin{array}{c}\text { Minimize } \hat{h} \text { SSEE } \\
\text { and minimize } \\
P M C_{b \mid a}\end{array}$ & $\hat{q}$ least squares \\
\hline
\end{tabular}

\footnotetext{
${ }^{1}$ This decision was made in an attempt to strike a balance between the dual objectives of performance estimation and fault diagnostics. Accurate turbomachinery deterioration estimation is necessary for performance trend monitoring purposes. Conversely, from a fault isolation standpoint accurate actuator bias estimation is secondary to the ability to discriminate between different fault types.
} 
First, an evaluation of the $\hat{h}$ estimation accuracy provided by the three Kalman filter designs was conducted. Theoretically predicted results are based on the analytical derivations found in Reference 12. Experimental results were obtained through a Monte Carlo simulation analysis where the first 10 health parameters varied over a random distribution in accordance with the covariance matrix, $P_{h}$. The test cases were provided to the C-MAPSS linear discrete state space model given in Equation (1), with an update rate of $15 \mathrm{~ms}$. Each individual health parameter test case lasted $30 \mathrm{~s}$, and a total of 200 test cases were evaluated. The experimental estimation errors were determined by calculating the mean squared error between estimated and actual values during the last $10 \mathrm{~s}$ of each $30 \mathrm{~s}$ test case. The error calculation is based on only the last $10 \mathrm{~s}$ so that engine model outputs and Kalman estimator outputs have reached a quasi-steady-state operating condition prior to calculating the error. This ensures that the experimental results are consistent with the theoretically predicted estimation errors that are derived assuming steady-state operation.

The theoretically predicted and the experimentally obtained $\hat{h}$ estimation error results are shown in Table 5. The best estimation accuracy is provided by Kalman filter design 1 . This is expected as this design has been optimized for estimating the first 10 health parameters. This produces a theoretical SSEE of 17.111. For the second and third Kalman filter designs, the theoretical $\hat{h}$ SSEE increases to 20.648 and 19.848 , respectively. For the second design the increase is due to adding three additional parameters to the health parameter vector. This increases the underdetermined nature of the estimation problem, causing a decrease in estimation accuracy.
In this case, the design choice to perform $V^{*}$ selection to minimize the estimation error in the first 10 health parameters was found to be helpful, but this design could not replicate the accuracy of the first Kalman filter. The third Kalman filter, like the first Kalman filter, is designed assuming 10 system health parameters. However, the dual optimization objectives of minimizing the $\hat{h}$ SSEE and the probability of misclassification applied in selecting $V^{*}$ causes an increase in $\hat{h}$ SSEE.

Next, an evaluation of the fault isolation accuracy provided by the three Kalman filter designs was assessed. Experimental results were obtained through simulation analysis where eight gas path fault cases of the type and magnitude shown in Table 3 were individually analyzed. These eight test cases were provided to the C-MAPSS linear discrete state space model shown in Equation (13), with 13 health parameters and an update rate of $15 \mathrm{~ms}$. Each test case was $300 \mathrm{~s}$ in duration, and a fault isolation assessment is conducted at each $15 \mathrm{~ms}$ time step $(20,000$ per test case). Only the health parameters associated with the fault under consideration were varied during each case. All remaining health parameters were left unchanged at their default values of zero.

The ensuing fault isolation results are shown in Table 6 through Table 8 . Table 6 shows the resulting fault isolation confusion matrix when using Kalman filter design 1 and the $\hat{q}$ analysis fault isolation approach. The elements along the diagonal of the confusion matrix represent correct isolation percentages. Perfect fault isolation performance is achieved for HPC, HPT, LPT, and Wf faults. Of the remaining faults, LPC, VSV and VBV are the most challenging to isolate. The overall correct isolation rate for this design is 90.5 percent.

TABLE 5.-HEALTH PARAMETER PERCENT SQUARED ESTIMATION ERRORS

\begin{tabular}{|c|c|c|c|c|c|c|c|c|c|c|c|c|}
\hline Estimator & Error type & $h 1$ & $h 2$ & $h 3$ & $h 4$ & $h 5$ & h6 & $h 7$ & $h 8$ & h9 & $h 10$ & SSEE \\
\hline \multirow{4}{*}{$\begin{array}{l}\text { Kalman } \\
\text { filter } \\
\text { design } 1\end{array}$} & Theor. squared bias & 0.007 & 0.065 & 0.112 & 0.474 & 0.073 & 0.124 & 0.044 & 0.033 & 0.144 & 0.035 & 1.111 \\
\hline & Theor. variance & 3.131 & 1.523 & 3.304 & 1.725 & 0.034 & 0.232 & 0.701 & 0.000 & 2.355 & 2.995 & 16.000 \\
\hline & Theor. squared error & 3.138 & 1.588 & 3.416 & 2.200 & 0.107 & 0.355 & 0.745 & 0.034 & 2.499 & 3.029 & 17.111 \\
\hline & Exper. squared error & 3.477 & 1.495 & 3.847 & 1.940 & 0.107 & 0.351 & 0.689 & 0.033 & 2.457 & 2.796 & 17.192 \\
\hline \multirow{4}{*}{$\begin{array}{l}\text { Kalman } \\
\text { filter } \\
\text { design } 2\end{array}$} & Theor. squared bias & 0.006 & 0.023 & 0.113 & 0.406 & 0.073 & 0.019 & 0.029 & 0.021 & 0.168 & 0.043 & 0.901 \\
\hline & Theor. variance & 3.146 & 2.084 & 3.306 & 1.834 & 0.039 & 1.780 & 0.843 & 1.219 & 2.411 & 3.084 & 19.747 \\
\hline & Theor. squared error & 3.152 & 2.107 & 3.419 & 2.240 & 0.112 & 1.799 & 0.871 & 1.240 & 2.579 & 3.128 & 20.648 \\
\hline & Exper. squared error & 3.388 & 2.196 & 3.836 & 2.039 & 0.110 & 1.833 & 0.776 & 1.402 & 2.619 & 3.001 & 21.200 \\
\hline \multirow{4}{*}{$\begin{array}{l}\text { Kalman } \\
\text { filter } \\
\text { design } 3\end{array}$} & Theor. squared bias & 0.051 & 0.101 & 0.117 & 0.269 & 0.074 & 0.129 & 0.039 & 0.032 & 0.170 & 0.014 & 0.996 \\
\hline & Theor. variance & 3.683 & 1.812 & 3.974 & 1.834 & 0.048 & 0.324 & 0.885 & 0.000 & 2.514 & 3.779 & 18.852 \\
\hline & Theor. squared error & 3.733 & 1.913 & 4.091 & 2.103 & 0.122 & 0.453 & 0.924 & 0.032 & 2.684 & 3.793 & 19.848 \\
\hline & Exper. squared error & 4.181 & 1.747 & 4.886 & 1.861 & 0.125 & 0.472 & 0.838 & 0.032 & 2.594 & 3.426 & 20.163 \\
\hline
\end{tabular}


TABLE 6.-CONFUSION MATRIX

(KF DESIGN 1, $\hat{q}$ LEAST SQUARES)

\begin{tabular}{|c|c|c|c|c|c|c|c|c|c|}
\hline & \multicolumn{8}{|c|}{$\begin{array}{l}\text { Isolated fault state } \\
(\%)\end{array}$} \\
\hline & & Fan & LPC & $\mathrm{HPC}$ & HPT & LPT & Wf & VSV & VBV \\
\hline \multirow{8}{*}{ 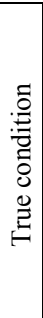 } & Fan & 99.0 & 0.0 & 0.0 & 0.0 & 1.0 & 0.0 & 0.0 & 0.0 \\
\hline & LPC & 0.1 & 77.8 & 12.0 & 6.4 & 0.0 & 1.3 & 0.3 & 2.2 \\
\hline & HPC & 0.0 & 0.0 & 100.0 & 0.0 & 0.0 & 0.0 & 0.0 & 0.0 \\
\hline & HPT & 0.0 & 0.0 & 0.0 & 100.0 & 0.0 & 0.0 & 0.0 & 0.0 \\
\hline & LPT & 0.0 & 0.0 & 0.0 & 0.0 & 100.0 & 0.0 & 0.0 & 0.0 \\
\hline & Wf & 0.0 & 0.0 & 0.0 & 0.0 & 0.0 & 100.0 & 0.0 & 0.0 \\
\hline & VSV & 2.1 & 2.8 & 1.6 & 1.5 & 3.3 & 2.3 & 82.5 & 3.9 \\
\hline & VBV & 3.2 & 8.2 & 2.2 & 5.8 & 5.3 & 4.1 & 6.1 & 65.1 \\
\hline \multicolumn{10}{|c|}{ Overall correct isolation rate $(\%)=90.5 \%$} \\
\hline
\end{tabular}

TABLE 7.-CONFUSION MATRIX

(KF DESIGN 2, MAXIMUM $\hat{h}$ )

\begin{tabular}{|c|c|c|c|c|c|c|c|c|c|}
\hline & \multicolumn{8}{|c|}{$\begin{array}{c}\text { Isolated fault state } \\
(\%)\end{array}$} \\
\hline & & Fan & LPC & HPC & HPT & LPT & Wf & VSV & VBV \\
\hline \multirow{8}{*}{ 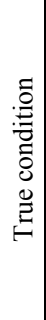 } & Fan & 14.8 & 45.2 & 8.5 & 21.2 & 10.4 & 0.0 & 0.0 & 0.0 \\
\hline & LPC & 0.0 & 82.3 & 14.9 & 2.7 & 0.0 & 0.0 & 0.0 & 0.0 \\
\hline & HPC & 0.0 & 0.8 & 99.2 & 0.0 & 0.0 & 0.0 & 0.0 & 0.0 \\
\hline & HPT & 0.0 & 0.1 & 0.0 & 99.9 & 0.0 & 0.0 & 0.0 & 0.0 \\
\hline & LPT & 11.6 & 17.0 & 0.0 & 2.6 & 68.8 & 0.0 & 0.0 & 0.0 \\
\hline & Wf & 0.0 & 0.9 & 0.0 & 0.0 & 0.0 & 99.1 & 0.0 & 0.0 \\
\hline & VSV & 0.1 & 54.0 & 42.4 & 3.1 & 0.5 & 0.0 & 0.0 & 0.0 \\
\hline & VBV & 0.2 & 92.5 & 5.9 & 1.2 & 0.2 & 0.0 & 0.0 & 0.0 \\
\hline \multicolumn{10}{|c|}{ Overall correct isolation rate $(\%)=58.0 \%$} \\
\hline
\end{tabular}

TABLE 8.-CONFUSION MATRIX

(KF DESIGN 3, $\hat{q}$ LEAST SQUARES)

\begin{tabular}{|c|c|c|c|c|c|c|c|c|c|}
\hline & \multicolumn{8}{|c|}{$\begin{array}{c}\text { Isolated fault state } \\
(\%)\end{array}$} \\
\hline & & Fan & LPC & HPC & HPT & LPT & Wf & VSV & VBV \\
\hline \multirow{8}{*}{ 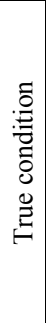 } & Fan & 97.6 & 0.0 & 0.0 & 0.0 & 2.2 & 0.0 & 0.0 & 0.2 \\
\hline & LPC & 0.1 & 90.7 & 3.6 & 0.1 & 0.0 & 0.9 & 0.0 & 4.6 \\
\hline & HPC & 0.0 & 0.0 & 100.0 & 0.0 & 0.0 & 0.0 & 0.0 & 0.0 \\
\hline & HPT & 0.0 & 0.0 & 0.0 & 100.0 & 0.0 & 0.0 & 0.0 & 0.0 \\
\hline & LPT & 0.0 & 0.0 & 0.0 & 0.0 & 100.0 & 0.0 & 0.0 & 0.0 \\
\hline & Wf & 0.0 & 0.0 & 0.0 & 0.0 & 0.0 & 100.0 & 0.0 & 0.0 \\
\hline & VSV & 1.3 & 2.8 & 1.9 & 2.1 & 3.5 & 1.6 & 85.6 & 1.3 \\
\hline & VBV & 6.8 & 11.2 & 0.3 & 0.2 & 2.1 & 3.9 & 0.1 & 75.6 \\
\hline \multicolumn{10}{|c|}{ Overall correct isolation rate $(\%)=93.7 \%$} \\
\hline
\end{tabular}

Table 7 shows fault isolation results obtained applying Kalman filter design 2 and making fault isolation decisions based on observed health parameter shifts. Here, an estimated magnitude for each of the five turbomachinery module faults was calculated as the root-sum-squared value of the module's efficiency and flow capacity $\hat{h}$ values. Actuator bias fault magnitudes were calculated by taking the absolute value of the corresponding $\hat{h}$ values. Fault isolation was then made by selecting the fault type with the largest estimated magnitude.
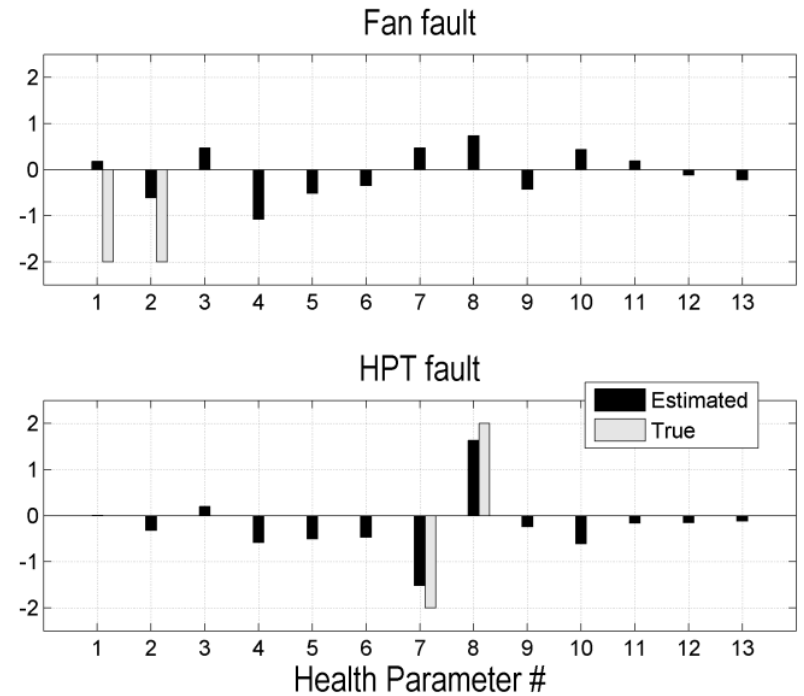

Figure 5.-Example of Kalman filter design 2 health parameter estimation during fan fault (top) and HPT fault (bottom).

The results in Table 7 show that while some faults such as HPC, HPT, and Wf are isolated with a high degree of accuracy, the overall fault isolation accuracy of 58 percent is relatively poor. In fact, faults such as Fan, VSV, and VBV are usually misclassified. This suggests that simply adding additional health parameters as part of the optimal tuner design process does not guarantee that the estimation accuracy of those health parameters will be adequate. In fact, in this case, which is attempting to simultaneously estimate 13 health parameters based on only 6 sensor measurements, there is a high degree of "smearing" of the estimates. This in turn results in unsatisfactory fault isolation performance. An illustration of the health parameter estimation results is shown in Figure 5 for a fan fault and an HPT fault. In the fan fault case (top plot), the Kalman filter is unable to provide good health parameter estimation, and consequently a fault misclassification will occur. In the HPT fault case (bottom plot), some smearing of the estimates across multiple health parameters is observed, but the largest estimated deviations are in health parameters 7 and 8 (HPT efficiency and flow capacity). Here, correct classification as an HPT fault will occur.

Table 8 shows confusion matrix results obtained using Kalman filter design 3 and the $\hat{q}$ analysis single fault isolation approach. Recall that this Kalman filter was designed with the objective of minimizing $\hat{h}$ SSEE and the probability of fault misclassification. The overall correct isolation rate is 93.7 percent, which is an improvement over the results shown in Table 6 and Table 7. This is encouraging as it demonstrates that selection of the $V^{*}$ matrix can have a positive impact on diagnostic performance. However, it is also acknowledged that this improvement in diagnostic performance comes at the 
expense of a slight degradation in performance estimation accuracy as previously shown in Table 5.

As a final comparison, an assessment of the fault isolation performance achievable through the analysis of sensor residuals is assessed. This serves as a baseline, and is representative of the fault diagnostic approaches shown in Figure 1 and Figure 3 designed to process $\Delta y$ information. Here, the fault isolation approach is designed to analyze the estimated $\hat{y}$ values produced by Kalman filter design $1 .^{2}$ This approach is the same as that described for processing the $\hat{q}$ estimates, but the confusion matrix and the measurement covariance matrix are updated to reflect sensed engine outputs. The results from this assessment, shown in Table 9, reveal that this approach provides fault isolation performance very similar to that shown in Table 6. This is very encouraging as it suggests that analyzing the estimated tuning parameters produced by the Kalman filter can yield isolation results of equivalent or better performance than the conventional approach of analyzing sensor residuals. Furthermore, the $\hat{q}$ analysis approach does not require a separate reference baseline model for residual calculation purposes. Conversely, $\Delta y$ analysis would require a reference or baseline model against which measurement residuals could be calculated.

TABLE 9.-CONFUSION MATRIX (KF DESIGN 1, $\hat{y}$ LEAST SQUARES)

\begin{tabular}{|c|c|c|c|c|c|c|c|c|c|}
\hline & \multicolumn{8}{|c|}{$\begin{array}{c}\text { Isolated Fault State } \\
(\%)\end{array}$} \\
\hline & & Fan & LPC & HPC & HPT & LPT & Wf & VSV & VBV \\
\hline \multirow{8}{*}{ 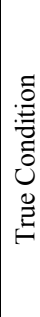 } & Fan & 99.0 & 0.0 & 0.0 & 0.0 & 1.0 & 0.0 & 0.0 & 0.0 \\
\hline & LPC & 0.1 & 76.1 & 13.1 & 7.2 & 0.1 & 1.7 & 0.3 & 1.6 \\
\hline & HPC & 0.0 & 0.0 & 100.0 & 0.0 & 0.0 & 0.0 & 0.0 & 0.0 \\
\hline & HPT & 0.0 & 0.0 & 0.0 & 100.0 & 0.0 & 0.0 & 0.0 & 0.0 \\
\hline & LPT & 0.0 & 0.0 & 0.0 & 0.0 & 100.0 & 0.0 & 0.0 & 0.0 \\
\hline & Wf & 0.0 & 0.0 & 0.0 & 0.0 & 0.0 & 100.0 & 0.0 & 0.0 \\
\hline & VSV & 2.3 & 2.9 & 1.6 & 1.6 & 3.4 & 2.3 & 83.1 & 2.8 \\
\hline & VBV & 4.0 & 8.2 & 2.8 & 6.4 & 6.5 & 5.2 & 7.4 & 59.5 \\
\hline \multicolumn{10}{|c|}{ Overall Correct Isolation Rate $(\%)=89.7 \%$} \\
\hline
\end{tabular}

\section{Conclusions}

The Kalman filter-based approach for combined aircraft engine performance estimation and gas path fault diagnostics has been shown to simplify implementation requirements without sacrificing performance. This simplification comes about by eliminating the need to maintain a second reference model for diagnostic purposes. Instead of analyzing sensor residuals to diagnose faults, it has been demonstrated that

\footnotetext{
${ }^{2}$ Estimated sensor measurements, $\hat{y}$, produced by the Kalman filter are used instead of actual sensor measurements, $y$, to conduct this comparison. The estimated values track measured values well and are less noisy, thus providing superior isolation performance.
}

direct analysis of the deviations in Kalman filter estimates can be performed for fault diagnostic purposes. In the context of this effort, two variations in the fault isolation approach were evaluated. Both approaches are based upon a previously developed optimal tuner selection methodology for underdetermined Kalman filter estimation applications. This methodology enables estimation of a set of model tuning parameters that can be transformed into a vector of health parameters reflecting engine performance deterioration. The first fault isolation approach expands the number of health parameters to encompass additional (actuator) fault types, and then conducts fault isolation based upon the estimated health parameter(s) that exhibit the largest change. The second fault isolation approach relies on the analytically derived open-loop quasisteady-state signature that a fault will produce in Kalman filter estimated tuning parameters. Here, fault isolation is performed by identifying the fault type signature that best matches the observed tuning parameters in a least squares sense. As a comparison, these two fault isolation techniques were compared against the conventional technique of performing fault isolation based upon sensor measurements. Simulation studies demonstrated that the first design did not provide ideal results. Due to the underdetermined nature of the estimation problem, individual faults were found to produce a "smearing" of estimates across multiple health parameters, including parameters not associated with the fault, which led to fault misclassification. Furthermore, adding additional health parameters to the design to account for actuator faults was found to compound the underdetermined nature of the problem. The fault isolation results were not ideal, and furthermore the estimation accuracy in the subset of health parameters reflective of performance deterioration worsened when the additional actuator bias health parameters were added to the design. Conversely, the second design was found to provide fault isolation accuracy comparable to that of the conventional approach of analyzing changes in engine sensed outputs. Furthermore, it was shown that an approximate measure for the probability of fault misclassification can be analytically formulated and incorporated into the optimal iterative search applied to select the Kalman filter tuning parameters, which was found to provide improved fault isolation performance. This modification did result in a decrease in performance deterioration estimation accuracy. The merits of its application are thus dependent upon end-user objectives.

The initial findings of this study have been encouraging. Follow-on evaluations are recommended to incorporate additional fault types and to consider larger variations in fault magnitudes. Additionally, evaluations are needed to assess the technique over a broader range of operating conditions. Due to system nonlinearities, it is reasonable to assume that the fault signatures contained within the estimated tuning parameters will vary as a function of engine operating point. If so, the 
proposed fault isolation approach will either require a means to archive/retrieve fault influence coefficient matrix information as a function of operating point, or it will be limited to performing fault isolation analysis at fixed operating conditions. Additional studies, such as closed-loop nonlinear simulation studies and actual aircraft engine data studies, are warranted to fully assess these design issues.

\section{References}

1. Society of Automotive Engineers E-32, (2005), “A Guide to the Development of a Ground Station for Engine Condition Monitoring," SAE Aerospace Information Report 4175A.

2. Volponi, A., Wood, B., (2005), "Engine Health Management for Aircraft Propulsion Systems," The Forum on Integrated System Health Engineering and Management (ISHEM) in Aerospace, November 7-10, Napa, CA.

3. Volponi, A.J., et al, (2003), "Gas Turbine Condition Monitoring and Fault Diagnostics”, Von Kármán Institute Lecture Series, VKI LS 2003-01, Rhode-Saint-Genèse, Belgium.

4. Doel, D. L., (1994), "TEMPER - A Gas Path Analysis Tool for Commercial Jet Engines," Journal of Engineering for Gas Turbines and Power, Vol. 116, No. 1, pp.82-89.

5. Urban, L.A., (1974), "Parameter Selection for Multiple Fault Diagnostics of Gas Turbine Engines," ASME Gas Turbine Conference and Products Show, paper 74-GT62, March 30-April 4, Zurich, Switzerland.

6. Y.G. Li, (2002), "Performance-Analysis-Based Gas Turbine Diagnostics: A Review," Proceedings of the Institution of Mechanical Engineers, Part A: J. Power and Energy, Vol. 216, pp. 363-377.

7. Luppold, R.H. Roman, J.R., Gallops, G.W., Kerr, L.J., (1989), "Estimating In-Flight Engine Performance Varaiations Using Kalman Filter Concepts," AIAA-892584, AIAA $25^{\text {th }}$ Joint Propulsion Conference, July 10-12, Monterey, CA.

8. Volponi, A., (2008), "Enhanced Self-Tuning On-Board Real-Time Model (eSTORM) for Aircraft Engine Performance Health Tracking," NASA CR-2008-215272.

9. Kumar, A., Viassolo, D., (2008), "Model-Based Fault Tolerant Control," NASA/CR-2008-215273.

10. Simon, D. L., (2010), “An Integrated Architecture for Onboard Aircraft Engine Performance Trend Monitoring and Gas Path Fault Diagnostics," Proceedings of The 2010 JANNAF Joint Subcomittee Meeting, Colorado Springs, CO, May 3-7.
11. Armstrong, J.B., Simon, D.L., (2011), "Implementation of an Integrated On-Board Aircraft Engine Diagnostic Architecture," AIAA-2011-5859, 47 ${ }^{\text {th }}$ AIAA Joint Propulsion Conference \& Exhibit, San Diego, CA, July 31August 3.

12. Simon, D.L., Garg, S., (2010), "Optimal Tuner Selection for Kalman Filter-Based Aircraft Engine Performance Estimation," Journal of Engineering for Gas Turbines and Power, Vol. 132/0231601-1.

13. Simon, D. L., Armstrong, J. B., Garg, S., (2011), "Application of an Optimal Tuner Selection Approach for On-Board Self-Tuning Engine Models," Proceedings of the ASME Turbo Expo 2011, GT2011-46408, June 6-10, Vancouver, BC, Canada.

14. Simon, D., (2006), Optimal State Estimation, Kalman, $H_{\infty}$, and Nonlinear Approaches, John Wiley \& Sons, Inc., Hoboken, NJ.

15. Ganguli, R., Dan, B., (2004), "Trend Shift Detection in Jet Engines Gas Path Measurements Using Cascaded Recursive Median Filter With Gradient and Laplacian Edge Detector," Journal of Engineering for Gas Turbines and Power, Vol. 126, No. 1, pp.55-61.

16. Ganguli, R., (2002), "Data Rectification and Detection of Trend Shifts in Jet Engine Path Measurements Using Median Filters and Fuzzy Logic," Journal of Engineering for Gas Turbines and Power, Vol. 124, No. 4, pp. 809-816.

17. DePold, H., Gass, F.,D., (1999), "The Application of Expert Systems and Neural Networks to Gas Turbine Prognostics and Diagnostics," Journal of Engineering for Gas Turbines and Power, Vol. 121, No. 4, pp. 607-612.

18. Provost, M. J., (2003), "Kalman Filtering Applied to Gas Turbine Analysis," Gas Turbine Condition Monitoring and Fault Diagnosis, Von Kármán Institute Lecture Series, VKI LS 2003-01, Rhode-Saint-Genèse, Belgium, 2003.

19. Borguet, S., Léonard, O., (2010), “A Sparse Estimation Approach to Fault Isolation," Journal of Engineering for Gas Turbines and Power, Vol. 132, No. 2, Article ID 021601.

20. Sorum, M.J., (1971), "Estimating the Conditional Probability of Misclassification," Technometrics, Vol. 13, No. 2, pp. 333-343.

21. Frederick, D.K., DeCastro, J.A., Litt, J.S., (2007), “User’s Guide for the Commercial Modular Aero-Propulsion System Simulation (C-MAPSS)," NASA/TM-2007-215026. 


\begin{tabular}{|c|c|c|}
\hline \multicolumn{2}{|c|}{ REPORT DOCUMENTATION PAGE } & $\begin{array}{l}\text { Form Approved } \\
\text { OMB No. 0704-0188 }\end{array}$ \\
\hline \multicolumn{3}{|c|}{$\begin{array}{l}\text { The public reporting burden for this collection of information is estimated to average } 1 \text { hour per response, including the time for reviewing instructions, searching existing data sources, gathering and maintaining the } \\
\text { data needed, and completing and reviewing the collection of information. Send comments regarding this burden estimate or any other aspect of this collection of information, including suggestions for reducing this } \\
\text { burden, to Department of Defense, Washington Headquarters Services, Directorate for Information Operations and Reports ( } 0704-0188) \text {, } 1215 \text { Jefferson Davis Highway, Suite } 1224 \text {, Allington, VA } 22222-2302 \text {. } \\
\text { Respondents should be aware that notwithstanding any other provision of law, no person shall be subject to any penalty for failing to comply with a collection of information if it does not display a currently valid OMB } \\
\text { control number. } \\
\text { PLEASE DO NOT RETURN YOUR FORM TO THE ABOVE ADDRESS. }\end{array}$} \\
\hline $\begin{array}{l}\text { 1. REPORT DATE (DD-MM-YYYY) } \\
01-10-2012\end{array}$ & $\begin{array}{l}\text { 2. REPORT TYPE } \\
\text { Technical Memorandum }\end{array}$ & 3. DATES COVERED (From - To) \\
\hline \multirow{3}{*}{\multicolumn{2}{|c|}{$\begin{array}{l}\text { 4. TITLE AND SUBTITLE } \\
\text { An Integrated Approach for Aircraft Engine Performance Estimation and Fault Diagnostics }\end{array}$}} & 5a. CONTRACT NUMBER \\
\hline & & 5b. GRANT NUMBER \\
\hline & & 5c. PROGRAM ELEMENT NUMBER \\
\hline \multirow{3}{*}{\multicolumn{2}{|c|}{$\begin{array}{l}\text { 6. AUTHOR(S) } \\
\text { Simon, Donald, L.; Armstrong, Jeffrey, B. }\end{array}$}} & 5d. PROJECT NUMBER \\
\hline & & 5e. TASK NUMBER \\
\hline & & $\begin{array}{l}\text { 5f. WORK UNIT NUMBER } \\
\text { WBS 284848.02.03.03.02.03 }\end{array}$ \\
\hline \multicolumn{2}{|c|}{$\begin{array}{l}\text { 7. PERFORMING ORGANIZATION NAME(S) AND ADDRESS(ES) } \\
\text { National Aeronautics and Space Administration } \\
\text { John H. Glenn Research Center at Lewis Field } \\
\text { Cleveland, Ohio 44135-3191 }\end{array}$} & $\begin{array}{l}\text { 8. PERFORMING ORGANIZATION } \\
\text { REPORT NUMBER } \\
\text { E-18439 }\end{array}$ \\
\hline \multirow{2}{*}{\multicolumn{2}{|c|}{$\begin{array}{l}\text { 9. SPONSORING/MONITORING AGENCY NAME(S) AND ADDRESS(ES) } \\
\text { National Aeronautics and Space Administration } \\
\text { Washington, DC 20546-0001 }\end{array}$}} & $\begin{array}{l}\text { 10. SPONSORING/MONITOR'S } \\
\text { ACRONYM(S) } \\
\text { NASA }\end{array}$ \\
\hline & & $\begin{array}{l}\text { 11. SPONSORING/MONITORING } \\
\text { REPORT NUMBER } \\
\text { NASA/TM-2012-217725 }\end{array}$ \\
\hline \multicolumn{3}{|c|}{$\begin{array}{l}\text { 12. DISTRIBUTION/AVAILABILITY STATEMENT } \\
\text { Unclassified-Unlimited } \\
\text { Subject Category: } 07 \\
\text { Available electronically at http://www.sti.nasa.gov } \\
\text { This publication is available from the NASA Center for AeroSpace Information, 443-757-5802 }\end{array}$} \\
\hline
\end{tabular}

\section{SUPPLEMENTARY NOTES}

\section{ABSTRACT}

A Kalman filter-based approach for integrated on-line aircraft engine performance estimation and gas path fault diagnostics is presented. This technique is specifically designed for underdetermined estimation problems where there are more unknown system parameters representing deterioration and faults than available sensor measurements. A previously developed methodology is applied to optimally design a Kalman filter to estimate a vector of tuning parameters, appropriately sized to enable estimation. The estimated tuning parameters can then be transformed into a larger vector of health parameters representing system performance deterioration and fault effects. The results of this study show that basing fault isolation decisions solely on the estimated health parameter vector does not provide ideal results. Furthermore, expanding the number of the health parameters to address additional gas path faults causes a decrease in the estimation accuracy of those health parameters representative of turbomachinery performance deterioration. However, improved fault isolation performance is demonstrated through direct analysis of the estimated tuning parameters produced by the Kalman filter. This was found to provide equivalent or superior accuracy compared to the conventional fault isolation approach based on the analysis of sensed engine outputs, while simplifying online implementation requirements. Results from the application of these techniques to an aircraft engine simulation are presented and discussed.

\section{SUBJECT TERMS}

Systems health monitoring; Gas turbine engines

\begin{tabular}{|c|c|c|c|c|c|}
\hline \multicolumn{3}{|c|}{ 16. SECURITY CLASSIFICATION OF: } & \multirow{2}{*}{$\begin{array}{l}\text { 17. LIMITATION OF } \\
\text { ABSTRACT } \\
\text { UU }\end{array}$} & \multirow{2}{*}{$\begin{array}{l}\text { 18. NUMBER } \\
\text { OF } \\
\text { PAGES } \\
20\end{array}$} & \multirow{2}{*}{$\begin{array}{l}\text { 19a. NAME OF RESPONSIBLE PERSON } \\
\text { STI Help Desk (email:help@sti.nasa.gov) } \\
\text { 19b. TELEPHONE NUMBER (include area code) } \\
\text { 443-757-5802 }\end{array}$} \\
\hline $\begin{array}{l}\text { a. REPORT } \\
\text { U }\end{array}$ & $\begin{array}{l}\text { b. ABSTRACT } \\
\text { U }\end{array}$ & $\begin{array}{l}\text { c. THIS } \\
\text { PAGE } \\
\text { U }\end{array}$ & & & \\
\hline
\end{tabular}



